\title{
Motivational Beliefs and Self-regulated Learning in Low Vocational Training Track Students
}

\author{
Jean-Louis Berger \\ Swiss Federal Institute for Vocational Education and Training \\ Avenue de Longemalle 1, Case Postale 192, 1000 Lausanne Malley 16, Switzerland \\ Tel: 41-21-621-8231Ｅ-mail: Jean-Louis.Berger@iffp-suisse.ch
}

Received: December 20, $2011 \quad$ Accepted: January 6, $2012 \quad$ Published: May 1, 2012

doi:10.5539/jedp.v2n1p37 URL: http://dx.doi.org/10.5539/jedp.v2n1p37

\begin{abstract}
The present study investigates students' self-regulation of cognition and motivation and how they relate to motivational beliefs across three topics. Three types of topic-specific motivational beliefs (self-efficacy beliefs, achievement goals, and perceived instrumentality) and cognitive (cognitive and metacognitive strategy use in reading comprehension, writing, and mathematics) and motivational self-regulation were assessed by self-report in a sample of 243 vocational students in low vocational training tracks. The results indicate that perceived instrumentality is the prominent predictor of cognitive self-regulation across the three topics whereas mastery goals and self-efficacy play a significant but minor role in that prediction.Moreover, a significant self-efficacy by perceived instrumentality interaction effect emerged regarding cognitive self-regulation in mathematics. Motivational self-regulation is predicted consistently by self-efficacy, mastery goals, and work-avoidance goals. The differential effects of motivational beliefs on the facets of self-regulation are discussed.
\end{abstract}

Keywords: Self-regulated learning, Vocational education and training, Motivation, Motivational beliefs, Strategy use

\section{Introduction}

The ability to self-regulate one's learning is recognized as an important determinant of school success and more generally as being crucial to lifelong learning (Boekaerts, 1997). Pintrich (2000) has defined self-regulated learning (SRL) as "an active, constructive process whereby learners set goals for their learning and then attempt to monitor, regulate, and control their cognition, motivation, and behavior, guided and constrained by their goals and the contextual features in the environment" (p. 453). An extended literature shows that SRL consistently relates to numerous motivational beliefs (Schunk \& Zimmerman, 2008; Zimmerman, 2011). Accordingly, SRL is described as a motivationally driven process: Due to the need for concentration, effort, and attentive self-reflection in applying self-regulation strategies, only the most valued skills or outcomes are typically self-regulated (Lens \& Vansteenkiste, 2008; Zimmerman, 2011). However, research has mainly focused on the regulation of cognition, i.e., the use of cognitive and metacognitive learning strategies, and less attention has been given to how the regulation of motivation relates to students' motivational beliefs (De Corte, Depaepe, \& Verschaffel, 2011; Wolters, 2011). Furthermore, most knowledge of SRL is based on students in primary to university programs, disregarding some groups of students, such as vocational students and students in the lower tracks of education, for whom improvements in SRL abilities may be more important as they tend to self-regulate to a lesser extent or with less efficiency than conventional students (Zimmerman, 2000). Bearing in mind the lack of studies considering several domains (or areas) of regulation such as the cognitive and motivational ones, and the limited evidence regarding vocational students with learning difficulties, the current study investigated the differential effect of multiple motivational beliefs (self-efficacy, goal orientation, and instrumentality) on the regulation of cognition and motivation in vocational students across several topics.

\subsection{Self-regulated Learning as Cognitive and Motivational Regulation}

While learning, students use strategies in order to acquire, understand, memorize, and transfer knowledge (Weinstein, Acee, \& Jung, 2011). In other words, they regulate their cognition for using adaptive strategies to learn the material. Cognitive regulation refers to selecting appropriate strategies such as rehearsal or organization 
(i.e., cognitive strategies), and overseeing learning using metacognitive strategies such as planning or monitoring (Brown, 1987). There is strong empirical evidence supporting the positive relationship between the degree of cognitive regulation and students' achievement (Zimmerman \& Martinez-Pons, 1988). In studies of SRL in vocational education, students are generally characterized by their teachers as cognitively passive when confronted with learning tasks (Elke et al., 2010): They do not spontaneously use strategies either because they do not know how to proceed or because they are not motivated to do so. While our own research has shown that they can learn self-regulation strategies successfully (Berger, Kipfer, \& Büchel, 2008), less is known about how their motivation influences their cognitive regulation.

In addition to students' ability to regulate their cognition, their capacity to regulate their motivation is known to have an important impact on the quality of their learning and their level of achievement (Wolters, 2003, 2011). In other words, students must use resource management strategies, modulate their effort (increase their persistence or time on task), and manage their affective and motivation processes to achieve their goals (Boekaerts, 1997; Corno, 2008; Kuhl, 1987). Some studies have even revealed that "self-discipline" is more important than intelligence and prior grades in school success explaining more variance than either of these two variables (Duckworth \& Seligman, 2005). Regulation of motivation could be represented by two perspectives: Students' use of strategies for the regulation of their motivation (Wolters, 2003), paralleling the use of learning strategies for cognitive regulation, or students' ability to regulate their motivation effectively (volitional perspective; Kuhl, 1984). The second perspective is adopted here, focusing on the extent to which a student can self-regulate rather than on the tools he or she can develop and use for self-regulation. Among the concepts developed to theorize this regulation, we have chosen "action control", introduced by Kuhl (1984), to represent regulation of motivation. Kuhl (1987) observed that although the expectancy-value theory can explain what individuals intend to do, it would best be extended to explicate to which extent they actually perform actions to realize these intentions; namely the ability to control the enactment of an intention. In this way, Kuhl enriched the expectancy-value theory through the addition of "action control", which may help explain the performance deficit observed by the learned helplessness phenomena. A basic distinction is made regarding the focus of attention in the time between the intention to reach a goal and performance of the necessary activities: Attention can focus on action-related information, thus facilitating performance, or on state-related information, thus hindering performance. State-orientation is potentially related to the processing of more information than what is necessary, whereas action-orientation may be related to a more parsimonious processing of information for attainment of a goal. Hence, action-oriented students have limited difficulties in enacting their intention even if they are faced with obstacles. For example, an action-oriented student faced with solving a challenging mathematical problem will initiate the solving process and persevere even if she cannot find a solution quickly. Contrarily, a state-oriented student in the same situation will tend to ruminate on the difficulty, become anxious, switch to another task or stop studying in favor of a more enjoyable activity such as watching TV (Kuhl, 1984).

\subsection{Motivational Beliefs, Regulation of Cognition, and Regulation of Motivation}

Numerous studies have indicated that motivational beliefs are predictive of SRL, which in turn explain school achievement (e.g., Hong \& Peng, 2008; Metallidou \& Vlachou, 2007; Pintrich \& DeGroot, 1990). Therefore, we consider motivational beliefs as predictors of SRL in the present study. Within the multiplicity of motivational beliefs, self-efficacy, achievement goals, and instrumentality were especially targeted for examination in relation to SRL. These associations are briefly reviewed below.

\subsubsection{Self-efficacy and SRL}

Self-efficacy is defined as the perceived capability to execute a task or to succeed in a specific topic (Bandura, 1997). Applied to students, this means the extent to which they feel able to learn a certain topic or successfully solve a task in school. Considerable evidence has documented the relationship between expectancy for success (typically assessed as self-efficacy beliefs) and the adaptive use of cognitive and metacognitive strategies. Student who have more confidence in their abilities to learn are better at monitoring their work time and modifying their learning strategy when necessary (Pajares, 2008). Berger \& Karabenick (2011) emphasized that in longitudinal studies, self-efficacy explained additional variance over time in higher-order cognitive and metacognitive strategy use; that is, higher self-efficacy is related to an increased use of deep-processing strategies over time. These results are supported by Borkowski, Chan, and Muthukrishna's (2000) heuristic developmental model of self-regulated learning, which assumes reciprocal effects of motivational beliefs and cognitive and metacognitive strategy use. According to this model, self-efficacy beliefs lead to the efficient use of learning strategies and improved performance, including the increased use of metacognitive strategies.

According to Schunk and Pajares (2005), self-efficacy beliefs are positively predictive of the quantity of effort 
students will exert on a task, how long they will persevere when facing difficulties, and how resilient they will be when confronted with adverse situations. This suggests a positive association between self-efficacy and ability to regulate one's motivation. Accordingly, Pajares' recent literature review (2008) concluded that the higher students' self-efficacy beliefs, the more persistence when confronted with challenges, regardless of prior achievement or ability.

\subsubsection{Achievement Goals and SRL}

The achievement goals framework postulates reasons students engage in learning, including the standard they use for judging their competencies (Pintrich, 2000). Several types of goals have been proposed to describe motivation to learn, such as mastery goals and work-avoidance goals. Mastery goals are adopted by students wanting to understand, master, and learn the material, whereas students aiming to be successful with the least effort embrace work-avoidance goals (Nicholls, 1989). Over the past 25 years, research on achievement goals and learning strategies has established strong connections between goals and the use of cognitive regulation strategies at the topic level. Most studies found that the use of learning strategies is positively correlated with mastery and negatively associated with work-avoidance goals (e.g., Dowson \& McInerney, 2001; Dupeyrat \& Mariné, 2005; Vrugt \& Oort, 2008). Furthermore, in a study with 263 vocational students learning professional mathematics, it was found that mastery goals were positively correlated with rehearsal, elaboration, and metacognitive strategies whereas work-avoidance goals were significantly correlated only with rehearsal strategies (Berger, 2012). This last type of strategies does not favor long term and flexible learning (Weinstein et al., 2011), which is indicative of the indirect effect achievement goals may have on learning.

Linnenbrink and Pintrich (2000) assume that the diverse types of achievement goals are linked differentially to behavioral processes and therefore to motivational regulation. Students adopting mastery goals would have a tendency to be highly persistent and to exert more effort in comparison to students adopting other types of goals. Contrarily, those adopting work-avoidance goals would tend to be less persistent and to regulate their motivation to a lesser degree. In one of the rare empirical studies on achievement goals and motivational regulation, Wolters and Rosenthal (2000) found that mastery goals were a consistent and strong predictor of the use of several types of strategies to regulate one's motivation.

\subsubsection{Perceived Instrumentality and SRL}

Husman and Lens (1999) have defined perceived instrumentality as "an individual's understanding of the instrumental value of a present behavior for the attainment of future goals" (p. 116). Research evidence indicates that instrumentality has a positive effect on cognitive and motivational regulations, contrary to other forms of extrinsic motivation based on rewards or punishments, which have been found to hinder students' SRL (Lens, Simons, \& Dewitte, 2002). In a study with 184 first-year nursing students, Simons, Dewitte and Lens (2004) investigated the effect of course perceived instrumentality on cognitive (deep vs. surface level of processing) and motivational (persistence) regulation. They found that the more students believed a course was useful for their future occupation, the more they persevered when studying for this same course. Although no direct effect on cognitive regulation was found, further path analysis of the data showed that perceived instrumentality indirectly predicted cognitive regulation through the mediation of task-orientation (akin to mastery goals). Similarly, in two empirical studies with 297 and 269 (respectively) high school students learning mathematics, Miller, Greene, Montalvo, Ravindran, and Nichols (1996) consistently found that perceptions of instrumentality of course performance to the attainment of future goals was predictive of the cognitive regulation, over and above the effect of achievement goals and perceived math ability (akin to self-efficacy). Accordingly, perceived instrumentality seems to play a key role in adolescents' SRL.

\subsection{Aim of the Study}

In sum, research evidence indicates that all motivational beliefs, be they self-efficacy, achievement goals or instrumentality, can sustain and trigger cognitive and motivational regulations. However, few studies have combined multiple motivational beliefs to investigate how they additively, and perhaps interactively, predict SRL. Moreover, studies with vocational students are rare, meaning that we do not know whether the patterns of relations between motivational beliefs and SRL in these students differ from what was observed with other types of students. Therefore, our aim in the present study is to investigate the motivational predictors of cognitive and motivational self-regulation in students in low vocational training tracks.

\section{Method}

\subsection{Participants}

The participants in this study were 243 vocational students in low-performing tracks. In accordance with school 
principals, they were recruited in three vocational schools in the area of Geneva, Switzerland. The criterion for inclusion in the sample was the type of vocational training (2-years of training leading to a Federal Certificate of Vocational education and training, an intellectually less demanding training than the typical 3-4 years of training leading to a Federal Diploma of Vocational education and training; Stalder \& Nägele, 2011). The mean age was 18 years and 8 months ( $S D=2$ yrs. 2 months), $61 \%$ were male and $39.9 \%$ were Swiss. They were apprentices in various professional fields, students from several fields being combined in the classes.

\subsection{Instruments}

In addition to demographic information related to sex, nationality, and age, participants completed several scales. The motivational beliefs (excluding instrumentality) and regulation of motivation in math and language scales were taken from the Questions about Learning (QaL; Büchel, Berger, \& Kipfer, 2011), a self-report instrument designed to assess motivation, social influences, and learning strategies in vocational students. Details about the construct validity of the QaL scales are available in Büchel et al. (2011). The regulation of cognition scales were designed for the present study. All items were rated on a 4-point Likert scale $(1=$ "not at all true of me" to $4=$ "very true of me" for the motivation items; 1 = "nearly never" to 4 "nearly always" for the cognitive and motivational regulation items).

\subsubsection{Motivational Beliefs}

Perceived instrumentality was assessed with a total of twelve items, four items for each of three subjects: Reading comprehension, writing (e.g., "Knowing how to correctly write a text will help me find a job after apprenticeship."), and mathematics. All of the items refer to the value the participants placed on their future (distal goal) rather than on passing the exam. The items assessing perceived instrumentality of mathematics were also used by Berger (2008) with vocational students; they were found to strongly load on a single factor and yield an internally consistent score $(\alpha=.77)$.

Self-efficacy beliefs were measured using two scales from the QaL (Büchel et al., 2011): Three items for language (e.g., "I feel able to succeed in reading, grammar and orthography.") and three items for mathematics (e.g., "I feel able to succeed in math problem solving."). In the QaL validation study (Büchel et al., 2011), this scale showed adequate internal consistency (respectively $\alpha=.69-.60$ ).

Mastery goals were assessed by six items from the QaL, three for math and three for language. These items measured the extent to which the student is oriented toward learning, understanding, and mastering the material (e.g., "I want to learn as much as possible in math."). In the QaL validation study, this scale showed adequate internal consistency (respectively $\alpha=.82-.68$ ).

Work-avoidance goals were assessed by six items from the QaL, three for math and three for language, and measured the extent to which the student is oriented toward doing the least effort necessary and avoiding the difficult or challenging tasks (e.g., "Do you wish to avoid doing math tasks that require to think a lot?"). In the QaL validation study, this scale showed adequate internal consistency (respectively $\alpha=.58-.59$ ).

\subsubsection{Regulation of Motivation}

Regulation of motivation was assessed by seven items for the language topic and seven items for the math topic in parallel. All items were from the QaL and measured the extent to which the student perceives herself or himself as able to regulate her or his motivation (e.g., "Even if I have to do difficult math tasks, I begin them right away."). In the QaL validation study, this scale showed adequate internal consistency (respectively $\alpha=.87$ $-.81)$.

\subsubsection{Regulation of Cognition}

Learning strategy scales were developed for three topics all students learn in vocational schools. Reading comprehension strategies were assessed with 11 items: Seven for cognitive strategies (e.g., "When I read a difficult text, I take notes.") and four for metacognitive strategies (e.g., "When I read the title and first lines, I ask myself what the text is about.").

Writing strategies were assessed with 13 items: Six for cognitive strategies (e.g., "When I write a text, I ask help if I have some doubts.") and seven for metacognitive strategies (e.g., "Before beginning to write a text, I take a while to think about what I am going to write.").

Mathematics strategies were assessed with 16 items: Nine for cognitive strategies (e.g., "When I learn mathematics, I try to establish relationships between what I learn in other topics.") and seven for metacognitive strategies (e.g., "When I am finished with a math task, I check my calculations."). 


\subsection{Procedure}

The author and a graduate assistant collected the data during whole-class sessions usually devoted to general knowledge courses. Students were first presented with the purpose of the study and told that their responses would be anonymous and participation was voluntary. Students completed the instruments in random order. Teachers were asked to leave the room during data collection so that the students felt comfortable responding freely.

\section{Results}

Exploratory factor analyses revealed that, within each topic, all cognitive and metacognitive strategy items loaded on a single factor rather than on two distinct factors. Therefore, students do not appear to distinguish in their answers the use of the two types of strategies; rather, they tend to use both strategies in concert. A confirmatory factor analysis was then performed specifying three factors, each representing regulation of cognition in the three topics. One item pertaining to reading comprehension strategies was removed for non-significant loading. Furthermore, four covariances between residuals were added to the CFA model, all justified by common wording in the items. The model fit was judged adequate given the large number of items: $\chi_{(683)}^{2}=1073.99, \chi^{2} / \mathrm{df}=1.57, \mathrm{RMSEA}=.05, \mathrm{CFI}=.83$. In comparison, a two factor model (one factor for reading comprehension and writing strategies and another for math) has a worse fit to the data $\left(\chi_{(701)}^{2}=1228.08\right.$, $\left.\chi^{2} / \mathrm{df}=1.75, \mathrm{RMSEA}=.06, \mathrm{CFI}=.79\right)$. Descriptive statistics, internal consistency, and correlations are shown in Table 1. Reliability ranges from $\alpha=.71$ to .88 . Most scales taken from the QaL have higher internal consistency in the present study than in the validation study (Büchel et al., 2011).

\section{Insert Table 1 Here}

As preliminary analyses, mean differences between topics were tested using paired-sample t-tests. The results show that students reported both more work-avoidance $(t(250)=3.409, p=.001$, Cohen's $d=0.26)$ and instrumentality $(t(250)=4.276, p<.001, d=0.25)$ for learning math than language. No significant differences were found for self-efficacy and mastery-goals. Regarding SRL, students reported using more learning strategies (i.e., more cognitive regulation) for math than for reading comprehension $(t(250)=3.244, p=.001, d=.0 .21)$ or redaction $(t(250)=2.987, p=.003, d=0.17)$. No significant difference was found between reading comprehension and redaction $(p=.47)$. Finally, the level of motivational regulation was found to be higher for language than for math $(t(250)=-2.388, p=.018 d=0.16)$.

Path analysis was then performed to investigate the relationships between motivational beliefs (predictors) and the two forms of SRL (outcomes). A single model was built, specifying paths from the four variables representing math motivational beliefs to the two variables representing SRL in math, and paths from the four motivational beliefs in language to the three SRL variables related to language (cognitive regulation in reading comprehension, in writing, and motivational regulation). The scores were then corrected for measurement error. After removing the non-significant paths, the model was found to fit the data well: $\chi_{(23)}^{2}=38.72, p=0.19$, RMSEA $=.03$, CFI $=.99$. Further, tests of interaction effects revealed that self-efficacy and perceived instrumentality interacted to significantly predict learning strategy use in mathematics. No such interaction effect was found in the prediction of learning strategies in reading comprehension or in writing/redaction. A summary of the path analysis results is shown in Tables 2 and 3 respectively for the topics of math and language.

\section{Insert Tables 2 and 3 Here}

\section{Discussion}

The present study examined the predictive role of motivational beliefs on SRL in a sample of low vocational training tracks students. Two domains of regulation (cognitive and motivational) were considered across three topics (reading comprehension, writing, and math). Three types of motivational beliefs (self-efficacy, goal orientation, and instrumentality) were included as predictors in addition to individual characteristics.

\subsection{The One-dimensionality of Cognitive Self-regulation within a Topic}

While the cognitive self-regulation scales were developed to assess two sub-forms of regulation (namely the use of cognitive and the use of metacognitive strategies), the results show that students do not discriminate in their answers between these two forms. There is thus a single empirical dimension on a continuum from low to high engagement in cognitive self-regulation. Similar results were found across the three topics and are in accordance with the results from others (e.g., Liu, 2009; Schraw \& Dennison, 1994). This one-dimensionality might be seen as a limitation due to the self-reported nature of the data: While students cognitively process such items, they may activate memories that relate not only to the specific self-regulation strategy in question but also to other strategies, leading to answers that may not be as precise as researchers would prefer (Berger \& Karabenick, 
2010). Note however that others studying SRL with think aloud or interview methods have also found the diverse strategies to be highly correlated and therefore explained by a single factor (Veenman, Elshout, \& Meijer, 1997; Zimmerman \& Martinez-Pons, 1988). Consequently, we might argue with Pintrich, Wolters, and Baxter's (2000) conclusion, from multiple studies revealing large interrelations between strategies, that "students who engage in one component of self-regulated learning also engage in other components. Accordingly, efforts to separate the different components into theoretically smaller subcomponents may not be justified by the empirical data" (p. 81). The present study indicates that whereas sub-forms of cognitive regulation cannot be empirically separated, cognitive and motivational regulations can be distinguished as they correlate only moderately.

\subsection{Mean Differences across Topics}

Several significant, though moderate, differences in motivational beliefs and SRL were found across topics. Vocational students consider math more useful than language. This mirrors results of several studies indicating that this group of students gives more importance to math considering it directly useful for the occupation they are learning (Berger, in press; Cretten, Lens, \& Simons, 2001; Prenzel, Kramer, \& Dreschel, 2002). Puzzlingly, work-avoidance goals were rated higher for math than for language, suggesting some incoherence in students' motivational beliefs that might be illustrated by the statement: "I believe math is useful but I am trying to do the least effort to learn it". A potential explanation is that these students, even while valuing a topic, are not willing to put forth the effort needed to learn due to their past struggles as low-achievers in mandatory schools: They may have found that hard work was not sufficient for success and therefore view effort as a "double-edged sword" (Covington \& Omelich, 1979). Furthermore, while students reported to regulate their cognition more intensely in math than in the two language topics, they reported the opposite for motivational regulation. The zero-order correlations however indicate that, across topics, both areas of regulation are positively associated. In sum, motivational beliefs and SRL are, as observed in other students and contexts, to some extent sensitive to the topic (Alexander, Dinsmore, Parkinson, \& Winters, 2011).

\subsection{The Prediction of Cognitive Self-regulation by Motivational Beliefs}

We established that perception of instrumentality is the main predictor or cognitive regulation across the three topics, explaining nearly one-third of the variance in learning strategy use. Moreover, we discovered an interaction effect self-efficacy $x$ instrumentality that is predictive of cognitive self-regulation in math. This means that expectancy and value work together to stimulate SRL: When students perceived both the topic to be useful and their ability to learn it to be high, they would then make the most use of learning strategies. Our results furthermore suggest that it may be beneficial to consider the additive and potentially interactive effects of several motivational beliefs when investigating the effects of motivation on SRL in order to obtain a more precise representation, mirroring the results of Miller et al. (1996).

The main and interaction effects of instrumentality indicate that this is a key motivational belief in vocational students that might distinguish these students from students in mandatory school or academic curricula. As students engaged in a vocational education program will likely anticipate that it would provide them with useful knowledge for their career, they may be disappointed if they do not perceive instrumentality in the content. This implies that to foster cognitive self-regulation, vocational teachers should focus on their students' perceptions of utility about the tasks and homework they are assigned. One way to accomplish this during instruction is to systematically provide a rationale when asking students to learn new material or simply to work on a task (Jang, 2008; Kember, Ho, \& Hong, 2008) or to ask students to think about task relevance (Hulleman, Godes, Hendricks, \& Harackiewicz, 2010), two strategies which have been found to be effective in increasing perceived instrumentality for low-performing students. In contrast, mastery goals and self-efficacy were found to have a smaller effect on cognitive self-regulation, contrary to the major role they have played in other studies. This could be attributed to sample specificity in the present study that contrasts with college or high school students on which most knowledge in the field of SRL is based. Therefore, the dynamic of SRL is sensitive to the type of students and contextual differences must be considered in the analysis of this dynamic. Our results call for more research on vocational students' SRL, notably to study how their regulations differ qualitatively and quantitatively from other students.

\subsection{The Prediction of Motivational Self-regulation by Motivational Beliefs}

In contrast to the predictors of cognitive self-regulation, achievement goals (mastery positively and work-avoidance negatively) together with self-efficacy, predict largely (between $49 \%$ and $67 \%$ of explained variance) the regulation of motivation both in language and math. Instrumentality plays no significant role here, in contrast to its huge importance in cognitive self-regulation, which is in accordance with Simons et al.'s (2004) results: Goal orientations were proximal predictors of motivational regulation whereas instrumentality has only 
an indirect and weak effect. Accordingly, sustaining motivation does not depend on the value of the task but on reasons why one is studying and one's beliefs about his or her ability to learn the material. These conclusions are consistent across topics and therefore robust. Implications are that vocational teachers should create classroom goal structure oriented toward mastery and help students foster confidence in their ability to learn.

In sum, the results indicate that there is a need to focus on motivational beliefs if we are to help vocational students to self-regulate their learning. This focus is complementary to strategic instruction aiming at teaching knowledge about learning strategies (Berger, Kipfer, \& Büchel, 2008; Borkowski et al., 2000).

\subsection{Limitations and Further Research}

One of the main limitations of this study is the exclusive reliance on self-report. Although the instruments demonstrate adequate psychometric properties, investigation of the validity of students' answers using non-psychometric methodology is warranted to shed light on how students understand, interpret, and formulate answers when questioned about their regulation. Cognitive interviewing or cognitive pretesting may provide such information and therefore, indicate how items could be improved for specific populations (Berger \& Karabenick, 2010; Karabenick et al., 2007). Another limitation concerns the cross-sectional research design that does not allow for a causal interpretation of the results. As some longitudinal studies (Berger \& Karabenick, 2011; Linnenbrink \& Pintrich, 2003; Zusho, Pintrich, \& Coppola, 2003) have revealed that motivation influences SRL rather than the opposite, the same reasoning was applied in the present study. It is however critical that longitudinal studies on vocational students' SRL be conducted to provide further information on direction of causality or reciprocal causation between motivational beliefs and SRL.

As recent research has shown that regulation is generally considered, even in adolescents' classrooms, to be the teacher's responsibility (De Corte et al., 2011; Kistner, Rakoczy, Otto, Dignath-van Ewijk, Büttner, \& Klieme, 2010), further study should investigate how to implement methods helping teachers support their students' use of self-regulation strategies in the classroom. The current study suggests that, as one part of this method, an indirect but efficient way to reach this goal is to change students' learning environment toward a mastery goal structure and to communicate rationales to students that help them see the instrumental value of what they are taught at vocational schools. These two paths of action will favor both cognitive and motivational regulation, which should increase the chance of school success for students in low tracks of vocational education.

\section{References}

Alexander, P. A., Dinsmore, D. L., Parkinson, M. M., \& Winters, F. I. (2011). Self-regulated learning in academic domains. In B. J. Zimmerman \& D. H. Schunk (Eds.), Handbook of self-regulation of learning and performance (pp. 393-407). New York: Routledge.

Berger, J.-L.(2008). Motivation, métacognition et aptitudes cognitives chez les apprenants de la formation professionnelle initiale [Motivation, metacognition, and cognitive aptitudes in vocational students]. $\mathrm{PhD}$ thesis, University of Geneva: Geneva, Switzerland. [Online] Available: http://archive-ouverte.unige.ch/vital/access/manager/Repository/unige:633

Berger, J.-L. (in press). Uncovering vocational students' multiple goal profiles in the learning of professional mathematics: Differences in learning strategies, motivational beliefs, and cognitive abilities. Educational Psychology. http://dx.doi.org/10.1080/01443410.2012.674663

Berger, J.-L. (2012). L'apprentissage autorégulé des mathématiques en formation professionnelle: croyances motivationnelles, compétences en raisonnement numérique et stratégies d'apprentissage [Self-regulated learning of mathematics in vocational education: Motivational beliefs, numerical reasoning abilities, and learning strategies]. Manuscript submitted for publication.

Berger, J.-L., \& Karabenick, S. A. (2010). How valid are self-reports of metacognitive strategies? Answer from a cognitive validity perspective. Paper presented at the fourth Biennial Meeting of the EARLI Special Interest Group on Metacognition, Münster, Germany, May 26-29.

Berger, J.-L., \& Karabenick, S. A. (2011). Motivation and students' use of learning strategies: Evidence of unidirectional influences in mathematics classrooms. Learning and Instruction, 21(4), 416-428. http://dx.doi.org/10.1016/j.learninstruc.2010.06.002

Berger, J.-L., Kipfer, N., \& Büchel, F. P. (2008). The effects of a metacognitive intervention for students in low performing vocational training tracks. Journal of Cognitive Education and Psychology [online], 8(1), 337-367.

Bandura, A. (1997). Self-efficacy: The exercise of control. New York: W.H. Freeman.

Boekaerts, M. (1997). Self-regulated learning: A new concept embraced by researchers, policy makers, educators, 
$\begin{array}{lllll}\text { teachers, and } \quad \text { students. } \quad \text { Learning } & \text { and }\end{array}$ http://dx.doi.org/10.1016/S0959-4752(96)00015-1

Borkowski, J. G., Chan, L. K. S., \& Muthukrishna, N. (2000). A process-oriented model of metacognition: Links between motivation and executive functioning. In G. Schraw \& J. C. Impara (Eds.), Issues in the measurement of metacognition (pp. 1-41). Lincoln, NE: Buros Institute.

Brown, A. L. (1987). Metacognition, executive control, self-regulation, and other more mysterious mechanisms. In F. E. Weinert \& R. H. Kluwe (Eds.), Metacognition, motivation, and understanding (pp. 65-116). Hillsdale, NJ: Erlbaum.

Büchel, F. P., Berger, J.-L., \& Kipfer, N. (2011). Fragen zum Lernen: Ein Instrument zur pädagogischen Diagnostik auf der Sekundarstufe I und II [Handbook for the instrument "Questions about Learning"]. Bern, Suisse: HEP Verlag.

Corno, L. (2008). Work habits and self-regulated learning: Helping students to find a "will” from a "way". In D. H. Schunk \& B. J. Zimmerman (Eds.), Motivation and self-regulated learning: Theory, research, and applications (pp. 197-222). New York: Lawrence Erlbaum.

Covington, M. V., \& Omelich, C. L. (1979). Effort: The double-edged sword in school achievement. Journal of Educational Psychology, 71(2), 169-182. http://dx.doi.org/10.1037//0022-0663.71.2.169

Cretten, H., Lens, W., \& Simons, J. (2001). The role of perceived instrumentality in student motivation. In A. Efklides, J. Kuhl, \& R. M. Sorrentino (Eds), Trends and prospects in motivation research (pp. 37-45). Dordrecht, The Netherlands: Kluwer.

De Corte, E., Depaepe, F., \& Verschaffel, L. (2011, August). Unraveling characteristics of powerful learning environments for self-regulation in mathematics. Paper presented at the Biennial EARLI Conference, Exeter. August 30 - September 3.

Dowson, M., \& McInerney, D. M. (2001). Psychological parameters of students' social and work avoidance goals: A qualitative investigation. Journal of Educational Psychology, 93, 35-42. http://dx.doi.org/10.1037//0022-0663.93.1.35

Duckworth, A. L., \& Seligman, M. E. P. (2005). Self-discipline outdoes IQ in predicting academic performance of adolescents. Psychological Sciences, 16, 939-944. http://dx.doi.org/10.1111/j.1467-9280.2005.01641.x

Dupeyrat, C., \& Mariné, C. (2005). Implicit theories of intelligence, goal orientation, cognitive engagement, and achievement: A test of Dweck's model with returning to school adults. Contemporary Educational Psychology, 30, 43-59. http://dx.doi.org/10.1016/j.cedpsych.2004.01.007

Elke, A., Grieder, S., Tiaden, C., Steiner, G., Metzger, C., Nüesch, C., Büchel, F. P., Berger, J.-L., \& Kipfer, N. (2010). Fostering learning competences in vocational education. In F. Oser, E. G. Renold, G. John, E. Winther \& S. Weber (Eds.), VET Boost: Towards a theory of professional competencies (pp. 149-174). Rotterdam, The Netherlands: Sense Publishers.

Hong, E., \& Peng, Y. (2008). Do Chinese students' perceptions of test value affect test performance? Mediating role of motivational and metacognitive regulation in test preparation. Learning \& Instruction, 18, 499-512. http://dx.doi.org/10.1016/j.learninstruc.2007.10.002

Hulleman, C. S., Godes, O., Hendricks, B. L., \& Harackiewicz, J. M. (2010). Enhancing interest and performance with a utility value intervention. Journal of Educational Psychology, 102(4), 880-895. http://dx.doi.org/10.1037/a0019506

Husman, J., \& Lens, W. (1999). The role of the future in student motivation. Educational Psychologist, 34(2), 113-125. http://dx.doi.org/10.1207/s15326985ep3402_4

Jang, H. (2008). Supporting students' motivation, engagement, and learning during an uninteresting activity. Journal of Educational Psychology, 100(4), 798-811. http://dx.doi.org/10.1037/a0012841

Karabenick, S. A., Wooley, M. E., Friedel, J. M., Ammon, B. V., Blazevski, J., Rhee Bonney, C. et al. (2007). Cognitive processing of self-report items in educational research: Do they think what we mean? Educational Psychologist, 42(3), 139-151. http://dx.doi.org/10.1080/00461520701416231

Kember, D., Ho, A., \& Hong, C. (2008). The importance of establishing relevance in motivating student learning. Active Learning in Higher Education, 9(3), 249-263.

Kistner, S., Rakoczy, K., Otto, B., Dignath-von Ewijk, C., Büttner, G., \& Klieme, E. (2010). Promotion of 
self-regulated learning in classrooms: Investigating frequency, quality, and consequences for student performance. Metacognition and Learning, 5(2), 157-171. http://dx.doi.org/10.1007/s11409-010-9055-3

Kuhl, J. (1984). Volitional aspects of achievement motivation and learned helplessness: Toward a comprehensive theory of action control. In B. A. Maher \& W. B. Maher (Eds.), Progress in experimental personality research (Vol. 13, Normal personality processes, pp. 99-171). Orlando, FL: Academic Press.

Kuhl, J. (1987). Feeling versus being helpless: Metacognitive mediation of failure-induced performance deficits. In F. E. Weinert \& R. H. Kluwe (Eds.), Metacognition, motivation and understanding (pp. 217-235). Hillsdale, NJ: Lawrence Erlbaum.

Lens, W., Simons, J., \& Dewitte, S. (2002). From duty to desire: The role of students' future time perspective and instrumentality perceptions for study motivation and self-regulation. In F. Pajares \& T. Urdan (Eds.), Academic motivation of adolescents (pp. 221-245). Greenwich, CT: Information Age Publishing.

Lens, W., \& Vansteenkiste, M. (2008). Promoting self-regulated learning: A motivational analysis. In D. H. Schunk \& B. J. Zimmerman (Eds.), Motivation and self-regulated learning: Theory, research, and applications (pp. 141-168). New York: Lawrence Erlbaum.

Linnenbrink, E. A., \& Pintrich, P. R. (2000). Multiple pathways to learning and achievement: The role of goal orientation in fostering adaptive motivation, affect, and cognition. In C. Sansone \& J. M. Harackiewicz (Eds.), Intrinsic and extrinsic motivation: The search for optimal motivation and performance (pp. 195-227). San Diego, CA: Academic Press.

Linnenbrink, E. A., \& Pintrich, P. R. (2003). The role of self-efficacy beliefs in student engagement and learning in the classroom. Reading \& Writing Quarterly, 19, 119-137.

Liu, O. L. (2009). Evaluation of a learning strategies scale for middle school students. Journal of Psychoeducational Assessment, 27(4), 312-322. http://dx.doi.org/10.1177/0734282908327935

Metallidou, P., \& Vlachou, A. (2007). Motivational beliefs, cognitive engagement, and achievement in language and mathematics in elementary school children. International Journal of Psychology, 42(1), 2-15. http://dx.doi.org/10.1080/00207590500411179

Miller, R. B., Greene, B. A., Montalvo, G. P., Ravindran, B., \& Nichols, J. D. (1996). Engagement in academic work: The role of learning goals, future consequences, pleasing others, and perceived ability. Contemporary Educational Psychology, 21, 388-422. http://dx.doi.org/10.1006/ceps.1996.0028

Nicholls, J. G. (1989). The competitive ethos and democratic education. Cambridge, MA: Harvard University Press.

Pajares, F. (2008). Motivational role of self-efficacy beliefs in self-regulated learning. In D. H. Schunk \& B. J. Zimmerman (Eds.), Motivation and self-regulated learning: Theory, research, and applications (pp. 111-139). New York: Lawrence Erlbaum.

Pintrich, P. R. (2000). The role of goal orientation in self-regulated learning. In M. Boekaerts, P. R. Pintrich \& M. Zeidner (Eds.), Handbook of self-regulation (pp. 451-502). San Diego, CA: Academic Press.

Pintrich, P. R., \& De Groot, E. V. (1990). Motivational and self-regulated learning components of classroom academic performance. Journal of Educational Psychology, 82(1), 33-40. http://dx.doi.org/10.1037/0022-0663.82.1.33

Pintrich, P. R., Wolters, C. A., \& Baxter, G. P. (2000). Assessing metacognition and self-regulated learning. In G. Schraw \& J. C. Impara (Eds.), Issues in the measurement of metacognition (pp. 43-97). Lincoln, NE: Buros Institute.

Prenzel, M., Kramer, K., \& Drechsel, B. (2002). Self-determined and interested learning in vocational education. In K. Beck (Ed.), Teaching and learning processes in vocational education (pp. 43-68). Frankfurt am Main, Germany: Peter Lang.

Schraw, G., \& Dennison, R. S. (1994). Assessing metacognitive awareness. Contemporary Educational Psychology, 19, 460-475. http://dx.doi.org/10.1006/ceps.1994.1033

Schunk, D. H., \& Pajares, F. (2005). Competence perceptions and academic functioning. In A. J. Elliot \& C. S. Dweck (Eds.), Handbook of competence and achievement motivation (pp. 85-104). New York: Guilford.

Schunk, D. H., \& Zimmerman, B. J. (Eds.). (2008). Motivation and self-regulated learning: Theory, research, and applications. New York: Lawrence Erlbaum. 
Simons, J., Dewitte, S., \& Lens, W. (2004). The role of different types of instrumentality in motivation, study strategies, and performance: Know why you learn, so you'll know what you learn! British Journal of Educational Psychology, 74, 343-360. http://dx.doi.org/10.1348/0007099041552314

Stadler, B. E., \& Nägele, C. (2011). Vocational education and training in Switzerland: Organisation, development and challenges for the future. In M. M. Bergman, S. Hupka-Brunner, A. Keller, T. Meyer \& B. E. Stadler (Eds.), Youth in transition in Switzerland: Results from the TREE panel study (pp. 18-39). Zürich, Switzerland: Seismo.

Veenman, M. V. J., Elshout, J. J., \& Meijer, J. (1997). The generality vs domain-specificity of metacognitive skills in novice learning across domains. Learning and Instruction, 7(2), 187-209. http://dx.doi.org/10.1016/S0959-4752(96)00025-4

Vrugt, A., \& Oort, F. J. (2008). Metacognition, achievement goals, study strategies and academic achievement: pathways to achievement. Metacognition and Learning, 3(2), 123-146. http://dx.doi.org/10.1007/s11409-008-9022-4

Weinstein, C. E., Acee, T. W., \& Jung, J. (2011). Self-regulation and learning strategies. New Directions for Teaching and Learning, 126, 45-53. http://dx.doi.org/10.1002/t1.443

Wolters, C. A. (2003). Regulation of motivation: Evaluating an underemphasized aspect of self-regulated learning. Educational Psychologist, 38(4), 189-205. http://dx.doi.org/10.1207/S15326985EP3804_1

Wolters, C. A. (2011). Regulation of motivation: Contextual and social aspects. Teachers College Records, 113(2), 265-283.

Wolters, C. A., \& Rosenthal, H. (2000). The relation between students' motivational beliefs and their use of motivational regulation strategies. International Journal of Educational Research, 33, 801-820. http://dx.doi.org/10.1016/S0883-0355(00)00051-3

Zimmerman, B. J. (2000). Attaining self-regulation. A social cognitive perspective. In M. Boekaerts, P. R. Pintrich \& M. Zeidner (Eds.), Handbook of self-regulation (pp. 13-39). San Diego, CA: Academic Press.

Zimmerman, B. J. (2011). Motivational sources and outcomes of self-regulated learning and performance. In B. J. Zimmerman \& D. H. Schunk (Eds.), Handbook of self-regulation of learning and performance (pp. 49-64). New York: Routledge.

Zimmerman, B. J., \& Martinez Pons, M. (1988). Construct validation of a strategy model of student self-regulated learning. Journal of Educational Psychology, 80(3), 284-290. http://dx.doi.org/10.1037//0022-0663.80.3.284

Zusho, A., Pintrich, P. R., \& Coppola, B. (2003). Skill and will: the role of motivation and cognition in the learning of college chemistry. International Journal of Science Education, 25(9), 1081-1094. http://dx.doi.org/10.1080/0950069032000052207 
Table 1. Descriptive statistics and correlations

\begin{tabular}{|c|c|c|c|c|c|c|c|c|c|c|c|c|c|c|c|c|c|c|c|}
\hline & Variable & $\mathrm{M}$ & SD & $\alpha$ & 2 & 3 & 4 & 5 & 6 & 7 & 8 & 9 & 10 & 11 & 12 & 13 & 14 & 15 & 16 \\
\hline \multicolumn{20}{|c|}{ Demographics } \\
\hline 1 & $\operatorname{Sex}(0=$ male, $1=$ female $)$ & 0.36 & -- & -- & -.00 & .02 & -.20 & .07 & .08 & .19 & .03 & -.10 & -.04 & .07 & .09 & .20 & -.11 & .08 & .10 \\
\hline 2 & Nationality $(0=$ Swiss, $1=$ Foreigner $)$ & 0.61 & -- & -- & -- & .03 & .03 & -.04 & .13 & .11 & .05 & .09 & .06 & .07 & .10 & .03 & .11 & .12 & .07 \\
\hline 3 & Age (years) & 18.59 & 1.74 & -- & & -- & .13 & .04 & .10 & .03 & -.02 & .02 & .14 & .16 & .09 & .04 & .22 & .19 & .22 \\
\hline \multicolumn{20}{|c|}{ Motivational beliefs } \\
\hline 4 & Self-efficacy beliefs in mathematics & 2.95 & 0.54 & .76 & & & -- & .20 & .41 & .17 & -.18 & -.02 & .23 & .17 & .41 & .07 & .38 & .15 & .14 \\
\hline 5 & Self-efficacy beliefs in language & 3.04 & 0.63 & .81 & & & & -- & .20 & .47 & .12 & -.40 & .09 & .21 & .16 & .55 & .17 & .25 & .29 \\
\hline 6 & Mastery goals in mathematics & 3.18 & 0.58 & .81 & & & & & -- & .36 & -.23 & -.17 & .42 & .40 & .50 & .25 & .46 & .27 & .20 \\
\hline 7 & Mastery goals in language & 3.25 & 0.61 & .81 & & & & & & -- & -.06 & -.41 & .26 & .42 & .36 & .62 & .27 & .37 & .36 \\
\hline 8 & Work-avoidance goals in mathematics & 2.63 & 0.67 & .71 & & & & & & & -- & .27 & -.18 & -.02 & -.29 & -.01 & -.09 & .03 & .03 \\
\hline 9 & Work-avoidance goals in language & 2.44 & 0.78 & .72 & & & & & & & & -- & -.10 & -.12 & -.27 & -.53 & -.07 & -.11 & -.10 \\
\hline 10 & Perceived instrumentality of mathematics & 3.20 & 0.64 & .78 & & & & & & & & & -- & .57 & .32 & .13 & .56 & .25 & .23 \\
\hline 11 & Perceived instrumentality of language & 3.05 & 0.56 & .84 & & & & & & & & & & -- & .23 & .27 & .50 & .49 & .49 \\
\hline \multicolumn{20}{|c|}{ Regulation of motivation } \\
\hline 12 & Action control in mathematics & 2.93 & 0.48 & .84 & & & & & & & & & & & -- & .42 & .39 & .28 & .29 \\
\hline 13 & Action control in language & 3.02 & 0.58 & .86 & & & & & & & & & & & & -- & .15 & .30 & .33 \\
\hline \multicolumn{20}{|c|}{ Regulation of cognition } \\
\hline 14 & Learning strategy use in mathematics & 2.64 & 0.53 & .88 & & & & & & & & & & & & & -- & .52 & .61 \\
\hline 15 & Learning strategy use in reading comprehension & 2.53 & 0.54 & .79 & & & & & & & & & & & & & & -- & .75 \\
\hline 16 & Learning strategy use in writing/redaction & 2.55 & 0.54 & .83 & & & & & & & & & & & & & & & -- \\
\hline
\end{tabular}

Note: correlations $\geq .13$ are significant at $\mathrm{p}<.05, \mathrm{r} \geq .17$ are significant at $\mathrm{p}<.01$, and $\mathrm{r} \geq .22$ are significant at $\mathrm{p}$ $<.001$

Table 2. Summary of path analysis for motivational beliefs and age predicting cognitive and motivational regulation in language

\begin{tabular}{|c|c|c|c|c|c|c|c|c|c|}
\hline \multirow{3}{*}{ Predictors } & \multicolumn{9}{|c|}{ Regulation of cognition and motivation in language } \\
\hline & \multicolumn{3}{|c|}{$\begin{array}{l}\text { Learning strategy use in } \\
\text { reading comprehension }\end{array}$} & \multicolumn{3}{|c|}{$\begin{array}{l}\text { Learning strategy use in } \\
\text { writing/redaction }\end{array}$} & \multicolumn{3}{|c|}{ Action control } \\
\hline & $\beta$ & $S E$ & $p$ & $\beta$ & $S E$ & $p$ & $\beta$ & $S E$ & $p$ \\
\hline Age & .13 & .07 & .050 & .14 & .06 & .013 & - & - & - \\
\hline Self-efficacy & - & - & - & .17 & .05 & .002 & .28 & .08 & .001 \\
\hline Mastery goals & .15 & .07 & .027 & - & - & - & .43 & .11 & $<.001$ \\
\hline Work-avoidance goals & - & - & - & - & - & - & -.27 & .08 & .001 \\
\hline Perceived instrumentality & .51 & .07 & $<.001$ & .53 & .06 & $<.001$ & - & - & - \\
\hline $\mathrm{R}^{2}$ & .40 & & & .40 & & & .67 & & \\
\hline
\end{tabular}

Note: Nationality and sex are not included in the table because neither were significant predictors of any dependent variable. All predictors are related to language. 
Table 3. Summary of path analysis for motivational beliefs predicting cognitive and motivational regulation in mathematics

\begin{tabular}{|c|c|c|c|c|c|c|}
\hline \multirow{3}{*}{ Predictors } & \multicolumn{6}{|c|}{ Regulation of cognition and motivation in mathematics } \\
\hline & \multicolumn{3}{|c|}{$\begin{array}{l}\text { Learning strategy use in } \\
\text { mathematics }\end{array}$} & \multicolumn{3}{|c|}{ Action control } \\
\hline & $\beta$ & $S E$ & $p$ & $\beta$ & $S E$ & $p$ \\
\hline Self-efficacy & .18 & .07 & .015 & .26 & .11 & .016 \\
\hline Mastery goals & .25 & .07 & $<.001$ & .40 & .10 & $<.001$ \\
\hline Work-avoidance goals & - & - & - & -.27 & .08 & $<.001$ \\
\hline Perceived instrumentality & .56 & .06 & $<.001$ & - & - & - \\
\hline Self-efficacy x Perceived instrumentality & .23 & .08 & .002 & - & - & - \\
\hline $\mathrm{R}^{2}$ & & .62 & & & .49 & \\
\hline
\end{tabular}

Note: Age, nationality and sex are not included in the table because none were significant predictors of any dependent variable. All predictors are related to mathematics. 